\section{Dor crônica e violência doméstica: estudo qualitativo com mulheres que freqüentam um serviço especializado de saúde}

\section{Chronic pain and domestic abuse: qualitative study with women who attend a specialized health service}

Anna Paula Florenzano de Almeida 1 Edinilsa Ramos de Sousa 2

Sandra Fortes 3

Maria Cecília de Sousa Minayo 4

\begin{abstract}
Objectives: to investigate the possibility of a history of abuse in women complaining of chronic pain who seek care in a unit specialized in treating pain at the Universidade Estadual do Rio de Janeiro, Brazil. Somatization was one of the main issues that made it possible to establish a link between chronic pain and abuse.

Methods: a case study was carried out using life history interviews with 11 patients, emphasizing histories of abuse and chronic pain.

Results: it was noticed that these patients show a great propensity to seek physical causes for their pains and that the difficulty in finding any such cause leads them through the health services from one doctor to another. All patients interviewed reported having never before spoken about their story of violence to any health care practitioner, and, when provided with the opportunity, these women were able to associate their pain not only to physical events, but also to emotional distress. The great majority of these patients sought refuge in religion as an alternative to the healing of their pain.

Conclusions: the study suggests the need for greater awareness of this connection between a history of abuse and chronic pain on the part of health care services and consequent investment in the education of the health care professionals to enable them to provide better care for these patients.
\end{abstract}

Key words Violence, Pain, Somatoform disorders
1 Instituto Fernandes Figueira. Fundação Oswaldo Cruz. Av. Rui Barbosa, 716. Rio de Janeiro, RJ, Brasil. CEP: 22.250-020. E-mail: ap.florenzano@uol.com.br

2,4 Centro Latino Americano de Estudos da Violência. Fundação Oswaldo Cruz. Rio de Janeiro, RJ, Brasil.

${ }^{3}$ Hospital Universitário Pedro Ernesto. Faculdade de Ciências Médica. Universidade do Estado do Rio de Janeiro, RJ, Brasil.

\section{Resumo}

Objetivos: investigar a existência de história de violência na vida de mulheres com queixa de dor crônica, e que solicitam atendimento em um serviço especializado no atendimento à dor da Universidade Estadual do Rio de Janeiro, Brasil. A somatização foi um dos temas destacados para se pensar a ligação entre violência e dor crônica.

Métodos: estudo de casos por meio da história de vida de 11 pacientes, enfatizando suas histórias de violência e vivência da dor.

Resultados: observou-se grande tendência das pacientes em buscar causas físicas para suas dores e nessa procura elas peregrinam pelos serviços de saúde passando de um médico ao outro. Todas as entrevistadas relataram nunca terem falado sobre suas histórias de violência com nenhum profissional de saúde e ao fazê-lo associam sua dor não somente a ocorrências físicas, como também a sofrimentos emocionais. Há uma busca da grande maioria das pacientes pela religião como alternativa para a cura da dor.

Conclusões: os resultados apontam para a necessidade dos serviços de saúde estarem mais atentos à conexão entre violência prévia e dores crônicas, investindo no preparo dos profissionais da área de saúde para atender a esses pacientes.

Palavras-chave Violência, Dor, Transtornos somatoformes 


\section{Introdução}

Têm crescido as evidências científicas de um elo entre as síndromes dolorosas crônicas e história de violência sexual e/ou física prévia, ${ }^{1-5}$ porém ainda há uma relativa escassez de estudos de pacientes portadores de dores crônicas explorando o possível impacto da violência sobre o desenvolvimento da doença, a aceitação e o desenrolar do tratamento, bem como sobre as distintas formas dos pacientes descreverem e lidarem com a dor.

Os pacientes de dor crônica com histórias prévias de violência têm maior probabilidade de diagnósticos médicos funcionais, em oposição aos orgânicos; maior tendência a utilizar os recursos dos serviços de saúde e maior probabilidade de ocorrência de dores em pontos específicos do corpo, como, por exemplo, dores abdominais/pélvicas, cefaléias. Ainda, pacientes portadores de dores abdominais crônicas sugerem uma relação positiva entre violências, diagnósticos funcionais e grande freqüência de utilização de serviços de saúde, tanto em práticas de encaminhamento como de atendimento primário para a manutenção da saúde.4,6-8

$\mathrm{O}$ esclarecimento dessa relação entre dor e violência possibilita um atendimento mais adequado e o serviço de saúde pode se organizar melhor. É possível, então, realizar diagnósticos mais apropriados, evitando a requisição repetida e desnecessária de exames complementares que sobrecarregam os serviços de saúde e implicam em custos também para o paciente. 9

As pesquisas desenvolvidas pela Antropologia Médica, citadas por Duarte, 10 Kirmayer e Young11 e Waitzkin e Magaña12 também têm abordado as queixas somáticas sem substrato anatômico, porém com um olhar diferente, a partir de métodos de pesquisa como a observação participante e voltados para a compreensão dos determinantes políticosociais destes quadros. Esses estudos têm oferecido importantes contribuições, demonstrando que tais sintomas representam, muitas vezes, formas de resistência e manipulação de um ambiente hostil, em especial quando se considera variáveis de gênero, tradicionalmente associadas à somatização.

No presente artigo considera-se, como em Kirmayer e Young, 11 o conceito de somatização preconizado por Lipowski (1988: 161):13

[...] a manifestação de sofrimento emocional através de queixas físicas, onde não se verificam lesões orgânicas compatíveis, mas sim patologias mentais e que leva a busca de atendimento médico.
Kirmayer e Young11 destacam que a somatização engloba também aspectos pessoais, familiares, assistenciais e sociais, podendo ser considerado um processo cultural, que inclui, mas não se restringe, à presença de patologia mental. Essa distinção é fundamental para que as pesquisas que hoje se desenvolvem nessa área possam considerar e respeitar essa diferença.

A somatização engloba essencialmente três aspectos, segundo Lipowski:13 a) experimental, que é a forma subjetiva como o indivíduo percebe seu corpo; b) cognitiva, que se refere ao fato de ele atribuir as alterações percebidas à doença física; e c) comportamental, que se refere a comunicações e ações compatíveis com essa interpretação, ao buscar auxílio médico.

Estudos enfatizam a importância da avaliação da violência em atendimentos ambulatoriais, visto que tais atendimentos podem funcionar como um espaço de apoio e de escuta que possibilita a elaboração do trauma. 12,14

O objetivo deste trabalho foi investigar histórias de violência na vida de mulheres com queixa de dor crônica. Ele é parte de uma pesquisa maior, da qual recortou-se a abordagem qualitativa. A pesquisa original estudou mulheres atendidas durante o mês de maio de 2000 em um serviço especializado em dor, ligado a um hospital universitário do Rio de Janeiro. Seu pressuposto foi de que mulheres que sofreram violência podem desenvolver um processo de somatização, onde a dor aparece como uma das queixas principais. Nessa pesquisa constatou-se que $93,4 \%$ das pacientes apresentaram histórias de violência verbal/simbólica, $90,1 \%$ de violência física e 46,2\% de violência sexual. 14

$\mathrm{O}$ enfoque da pesquisa recai sobre a figura da mulher por ser essa, além de uma das principais vítimas de violência, o sujeito social que mais se apresenta no ambulatório da clínica de dor onde a pesquisa foi realizada.

Nesse artigo recorta-se as falas de mulheres com dores crônicas e histórias prévias de violência, investigando como as pacientes percebem e dão significado a essa vivência, se a relaciona às dores que sentem e qual é, na sua visão, a postura dos profissionais de saúde na investigação de suas história de violência.

\section{Métodos}

Realizou-se um estudo de casos explorando a existência ou não de história de violência em mulheres com dor crônica, atendidas em uma clínica de saúde 
especializada em dor do Hospital Universitário Pedro Ernesto (HUPE) da Universidade Estadual do Rio de Janeiro (UERJ), em maio de 2000, na cidade do Rio de Janeiro.

Trata-se de um serviço ligado a um hospital universitário, para onde todos os pacientes são encaminhados após uma triagem nos ambulatórios gerais do hospital, garantindo, assim, uma certa especificidade e homogeneidade quanto às queixas deles.

Na pesquisa original foram aplicadas três escalas (Questionário de avaliação de distúrbios mentais para atenção primária (Prime MD), Escala de Conflitos (Conflict Tactics Scales-CTS), Questionário de violência física e sexual) a 91 mulheres atendidas no serviço, que permitiram diagnosticar a existência de violência verbal/simbólica, física e sexual e de transtornos mentais mais freqüentes nas histórias de vida delas. Em um segundo momento, realizou-se uma entrevista do tipo história de vida com 11 pacientes que apresentaram diagnóstico positivo para histórias de violência nas escalas.

Para que se tivesse maior diversidade de casos, adotou-se como critério, para a escolha das pacientes a serem entrevistadas, a presença de diferentes histórias de violência, diferentes tipos de agressores, diagnóstico de dor crônica em pacientes que tivessem maior possibilidade de serem somatizadoras (dor sem substrato físico condizente).

A entrevista buscou investigar o passado, cotidiano, tipos de relacionamentos (familiares, comunitários, conjugais), opiniões, valores e crenças dessas mulheres. Segundo Pereira de Queiroz,15 define-se história de vida como o relato de um narrador sobre sua existência através do tempo, tentando reconstituir os acontecimentos que vivenciou e transmitir a experiência que adquiriu. A análise qualitativa, assim como aponta Minayo, 16 considera que é através da linguagem que o sujeito social expressa suas vivências, valores e ideologias.

As entrevistas abordaram a família de origem (acontecimentos da infância, relacionamentos com os pais/cuidadores e com irmãos, história de violência doméstica na família); a família constituída (relacionamentos com o companheiro e com os filhos, ocorrência de violência); e história de vivência da dor (início da dor, percepção de fatores associados à dor, o que ou quem procuram em busca de ajuda). Duraram em média uma hora e meia com cada paciente, sendo gravadas com a devida autorização das entrevistadas e transcritas, tendo-se o cuidado de se manter o conteúdo original das falas.

Para a análise, tomou-se como base a Técnica de Análise Temática proposta por Bardin 17 e balisada pelos princípios de Minayo. 18
Para a apresentação dos dados das pacientes entrevistadas foram adotados nomes fictícios. Algumas falas apresentadas sofreram pequenas modificações, objetivando melhorar a compreensão sem modificar a estrutura das respostas. Em outras, algumas expressões foram mantidas, apesar de estranhas às normas gramaticais.

A pesquisa foi aprovada pelo Comitê de Ética do Instituto Fernandes Figueira da Fundação Oswaldo Cruz, ao qual estava vinculada, bem como foi devidamente autorizada pela direção do hospital onde foi desenvolvida.

\section{Resultados}

Na Tabela 1, é apresentado o perfil socioeconômico das entrevistadas, de forma a facilitar a compreensão, contendo seus nomes fictícios, suas idades, escolaridade, estado civil (se tem ou não companheiro), renda pessoal, renda familiar, diagnóstico e tempo de tratamento na clínica de dor.

\section{Histórias de violência e de vivência da dor}

Patrícia, diagnosticada como "dor do lado esquerdo", relata sentir dores há aproximadamente quatro anos. Como ela mesma diz: "É uma dor que não passa nunca". Tem dores em todo o lado esquerdo do corpo:

\section{[...] uma dor que começa no coração, e vai se espalhando pelo corpo, vai me sufocando, aí eu entro em crise.}

Já fez exames do coração, do pulmão, da coluna, da cabeça, e nunca foi encontrado nada.

\footnotetext{
[...] Eu só sei que eu quero descobrir de onde vem essa dor, porque eu quero curar ela, que eu não tenho mais vontade de viver.
}

Foi vítima de abuso sexual do pai.

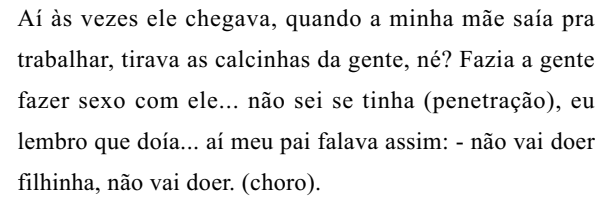

São muitas as tentativas de se explicar a causa da dor para a qual não se encontram motivos físicos. Patrícia se diz "igual a um ping-pong" pois um médico encaminha para outro, que por sua vez manda para outro, que manda fazer fisioterapia. "Faz 
Dados sobre as 11 pacientes entrevistadas da Clínica de Dor do Hospital Universitário Pedro Ernesto (HUPE) da Universidade Estadual do Rio de Janeiro, na cidade do Rio de Janeiro, maio de 2000.

\begin{tabular}{|c|c|c|c|c|c|c|c|}
\hline $\begin{array}{l}\text { Paciente } \\
\text { (nome fictício) }\end{array}$ & $\begin{array}{l}\text { Idade } \\
\text { (em anos) }\end{array}$ & Escolaridade & Estado civil & $\begin{array}{l}\text { Renda } \\
\text { pessoal } \\
(\text { em S.M*) }\end{array}$ & $\begin{array}{l}\text { Renda } \\
\text { familiar } \\
\text { (em S.M*) }\end{array}$ & Diagnóstico & $\begin{array}{l}\text { Tempo de } \\
\text { tratamento na } \\
\text { Clínica de Dor }\end{array}$ \\
\hline Ariane & 32 & $\begin{array}{l}\text { Primeiro grau } \\
\text { completo }\end{array}$ & Casada & Sem renda & $4-6$ & Cefaléia & Dois anos \\
\hline Célia & 52 & $\begin{array}{l}\text { Não sabe ler } \\
\text { e escrever }\end{array}$ & $\begin{array}{l}\text { Solteira/ } \\
\text { tem companheiro }\end{array}$ & $1-3$ & $1-3$ & Hérnia de disco & Seis anos \\
\hline Teresa & 56 & $\begin{array}{l}\text { Segundo grau } \\
\text { incompleto }\end{array}$ & Viúva & $1-3$ & $1-3$ & Lombalgia & Dois anos \\
\hline Mirian & 62 & $\begin{array}{l}\text { Não sabe ler } \\
\text { e escrever }\end{array}$ & Casada & $1-3$ & $1-3$ & Lombalgia & Seis meses \\
\hline Neli & 41 & $\begin{array}{l}\text { Primeiro grau } \\
\text { completo }\end{array}$ & $\begin{array}{l}\text { Solteira/ } \\
\text { tem companheiro }\end{array}$ & $1-3$ & $1-3$ & Fibromialgia & Cinco anos \\
\hline Rosa & 42 & $\begin{array}{l}\text { Primeiro grau } \\
\text { incompleto }\end{array}$ & $\begin{array}{l}\text { Viúva/ } \\
\text { tem namorado }\end{array}$ & $1-3$ & $1-3$ & Paralisia de mão & Dois anos \\
\hline Simone & 61 & $\begin{array}{l}\text { Superior } \\
\text { completo }\end{array}$ & Casada & +6 & +6 & Hérnia de disco & Dois anos \\
\hline Dora & 43 & $\begin{array}{l}\text { Primeiro grau } \\
\text { completo }\end{array}$ & Casada & $1-3$ & $1-3$ & Hérnia de disco & Três anos \\
\hline Ivone & 39 & $\begin{array}{l}\text { Primeiro grau } \\
\text { incompleto }\end{array}$ & $\begin{array}{l}\text { Separada/ } \\
\text { tem companheiro }\end{array}$ & $1-3$ & $1-3$ & Lombalgia & Dois anos \\
\hline Luisa & 48 & $\begin{array}{l}\text { Segundo grau } \\
\text { completo }\end{array}$ & Separada & $1-3$ & $1-3$ & $\begin{array}{l}\text { Distrofia simpático } \\
\text { reflexa }\end{array}$ & Um ano \\
\hline Patrícia & 36 & $\begin{array}{l}\text { Primeiro grau } \\
\text { incompleto }\end{array}$ & Separada & $1-3$ & $1-3$ & $\begin{array}{l}\text { Dor do lado } \\
\text { esquerdo }\end{array}$ & Um ano \\
\hline
\end{tabular}

* S.M=salário mínimo ( $R \$ 150,00$, em maio de 2000).

isso, faz aquilo e nada curava a dor, nada". É sempre muito confuso para Patrícia entender o porquê do médico lhe receitar "... um montão de calmante", e a mesma "tomar aquele calmante todinho", e continuar "a mesma coisa, a mesma dor".

Tem lembranças de que a primeira vez que teve crise foi quando seu segundo companheiro a levou para um morro para comprar drogas. Teve contato com muitas armas e com muita droga. Porque quis chamar a polícia, seu marido a forçou a fumar maconha:

[...] Ele me fez fumar. Eu não queria, eu vi aquele monte de arma na minha frente. Poderia a qualquer minuto sair um tiro daquelas armas e me pegar. Foi ali que eu criei o pânico da morte.

Sentiu todo o seu corpo repuxar e foi levada para o hospital. Lá o médico prescreveu-lhe um calmante pedindo que procurasse um psiquiatra. Certa feita, Patrícia estava passeando em uma cachoeira e viu uma mulher lavando outra mulher. Começou, então, a se sentir suja, querendo se lavar com a água da cachoeira, querendo sair correndo. Sentiu um aperto, como se algo a estivesse sufocando. No hospital os médicos tiveram o mesmo procedimento anterior. Patrícia continuava do mesmo jeito, chorando o tempo todo, em depressão profunda. Chegou a procurar um psiquiatra, que se comportou da mesma maneira que os outros médicos: receitou calmantes e a dispensou.

Todas as pacientes têm um longo trajeto de busca de tratamento até chegarem neste serviço de atendimento à dor:

[...] eu comecei a procurar vários hospitais. Eu fui na rua 
do Resende, aí eu tive em Botafogo, no Instituto de Neurologia Deolindo Couto..., conversei com o médico dos Servidores... fui também para o HTO (Hospital de Traumato Ortopedia); no HTO, eu fiz raio-x e tudo; aí, o médico me encaminhou aqui pra clínica da dor... (Neli, fibromialgia).

\section{Dor e suas possíveis causas}

Quando perguntadas sobre as causas de suas queixas de dor, observou-se uma grande tendência nas pacientes em responder apontando para causalidades físicas. Em alguns casos, principalmente após falarem sobre suas vivências de violência e humilhações, as pacientes apontaram tais acontecimentos como tendo algum tipo de relação com seu sintoma de dor crônica, mesmo sem entender muito bem como um sofrimento emocional possa estar desencadeando uma sensação física. Um exemplo disso é Neli, que sofre de fibromialgia, quando relata que acha que suas dores pioram

[...] talvez por essas coisas guardadas do passado, ter visto minha mãe e meu pai transando no meio da rua, ou talvez, foi por eles beberem muito e isso pode ter passado no sangue para nós os filhos.

Em alguns momentos Patrícia (dor do lado esquerdo) relaciona fatos de sua vida nos quais houve sofrimento emocional com a dor que sente, como, por exemplo, quando diz que ao pensar no abuso sexual que sofreu de seu pai, sua dor aumenta: "... aí que vem aquela dor que começa no coração e vai sufocando". Como tem medo de morrer, começa a entrar em "crise", então pede para ser levada rapidamente para o hospital.

Ariane sofre de dor de cabeça há oito anos. Foi vítima de violência de seu pai e relata que não só ela, mas também toda a família, inclusive sua mãe, sofreram violência:

[...] Acho que a família toda. Gritos, muitos gritos... Inclusive a física né? Porque nessa última vez teve agressão. Você vê uma pessoa ameaçando que vai bater na sua mãe, você fica pensando que vai bater em você. Aí com certeza. Teve pedaço de pau. Nesse sentido eu já senti violência sim.

A primeira vez que teve dores muito fortes foi uma semana depois do nascimento de seu filho. Consultou-se com um médico em uma cidade do interior do estado, o qual disse que ela devia ter quebrado o resguardo e por isso estava com essas dores. A partir daí nunca mais teve sossego, sempre tendo muita dor de cabeça. Tentou mudar de médico, porém como esse também não conseguiu dizer o que ela tinha, apenas diagnosticou uma cefaléia, ela não conseguiu tomar os remédios que lhe foram prescritos:

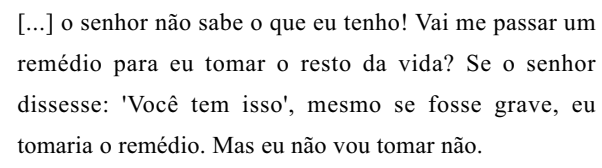

Há aproximadamente dois anos Ariane está se tratando na Clínica de Dor do HUPE. Diz ter confiança em sua médica, mas também não consegue tomar a medicação que lhe é prescrita, pois tem medo dos efeitos colaterais dos remédios como, por exemplo, ter dor de estômago, perder o sono, ter problemas nos rins. Por conta disso, às vezes toma um analgésico por conta própria para aliviar sua dor. Ariane reconhece que não devia fazer isso, porém não consegue agir diferente. Durante a entrevista, ao relatar o seu relacionamento com o pai, do qual guarda muitas lembranças de violência, Ariane chegou a questionar se seu problema de saúde, assim como o de suas duas irmãs, pode estar relacionado com sua história de vida:

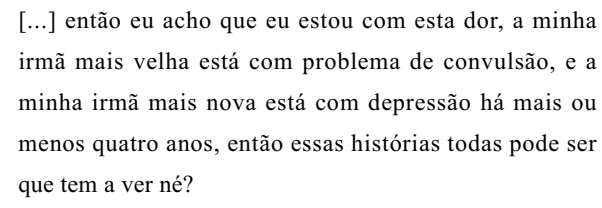

[...] então eu acho que eu estou com esta dor, a minha irmã mais velha está com problema de convulsão, e a minha irmã mais nova está com depressão há mais ou menos quatro anos, então essas histórias todas pode ser que tem a ver né?

No caso de Célia, ela teve uma queda no trabalho há aproximadamente 12 anos. Depois disso começou a sentir muitas dores nas costas e não estava conseguindo andar. Então descobriu que tinha hérnia de disco. Passou por uma cirurgia, que segundo ela, não melhorou em nada sua dor. Com isso, passou a se tratar no ambulatório da Clínica de Dor. Fez seis bloqueios analgésicos e a sua dor continuou. Foi encaminhada para a saúde mental e fez sessões com a psicóloga sem muito sucesso. É interessante ressaltar que Célia, em nenhuma das sessões, contou para a psicóloga sua história de abuso sexual, que ocorreu na infância, com um irmão:

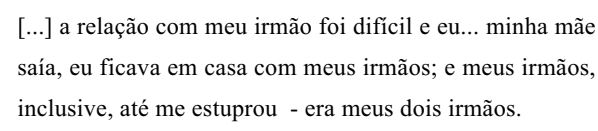

Célia teve muita dificuldade em falar sobre o tema, dizendo que têm coisas do passado que não valem a pena serem mexidas. 
[...] é uma coisa, assim, que marca, que não tem volta, vou contar pra que, quer dizer, posso contar pra você, mas sabe quando você tem uma coisa no coração que... sou eu e Deus.

Porém, durante a entrevista, a paciente, ao se referir ao tratamento dela, disse que na verdade "o meu problema está dentro de casa", pois o irmão que a violentou sexualmente quando criança hoje é um doente mental, e está sob seus cuidados, o que Célia relata ser muito difícil para ela:

[...] eu acho que o meu problema esta dentro de minha casa, com o meu próprio irmão doente mental; porque eu acho que quando a gente tá doente, a gente tem que conseguir se tratar e ficar sempre em contato com aquelas lembranças é muito difícil!.

\section{Busca de ajuda na religião}

É interessante ressaltar a busca da maioria das pacientes por uma religião, como uma alternativa para a cura da dor. Em geral, a igreja mais procurada foi a Igreja Universal do Reino de Deus. Todas as pacientes que procuraram essa igreja acabaram se afastando depois, pois perceberam que as promessas de cura não se concretizaram. Muitas vezes as pacientes se culpam por não terem sido curadas, pois não tiveram fé suficiente:

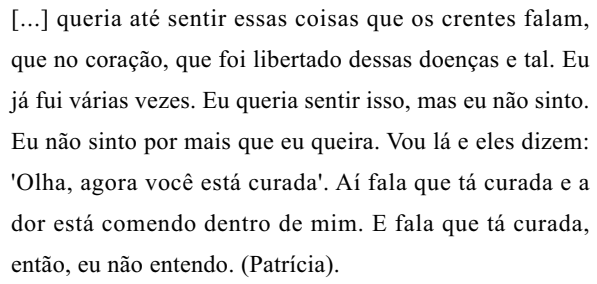

Teresa, que tem o diagnóstico de lombalgia, se diz cristã desde que nasceu, é da Igreja Batista, assim como todos os seus filhos. Para ela, Deus pode operar o milagre da cura de sua dor, e se isso não está acontecendo é porque Ele quer que ela sirva de testemunho para outras pessoas:

[...] de repente Ele quer que eu testemunhe com esse sofrimento. Testemunhe para outros, a minha paciência, a minha calma, a minha tranqüilidade, a minha fé, a minha confiança. De repente Ele me quer assim pra isso. E se Ele não quer pra isso, ele pode fazer a cura, de uma hora pra outra.

Para Teresa, a violência é uma manifestação do adversário de Deus:
[...] então, quer dizer, briga, briga é uma coisa que não é de Deus. Quer dizer. Deus permite. Tudo no mundo foi ele que fez. Mas não é uma coisa que ele gosta. Onde há briga, onde há discórdia, o adversário de Deus está no meio. Está atrapalhando, está atuando.

\section{Atuação dos profissionais de saúde}

Todas as pacientes entrevistadas relataram nunca terem falado sobre suas histórias de violência com nenhum profissional de saúde. As justificativas para isso são muitas, como no caso de Patrícia, que diz ter vergonha de falar sobre esse assunto, pois não sabe o que é mais vergonhoso: dizer que foi abusada por seu pai, ou falar do abuso em si. Patrícia chegou a contar para o seu primeiro marido o abuso sexual que sofria do pai, porém, nos momentos de bebedeira, seu marido ficava lhe humilhando, repetindo várias vezes que ela tinha sido mulher do próprio pai. Esse fato a traumatizou, e com isso ela nunca mais contou para ninguém "eu nunca falei, estou falando agora pela primeira vez".

Segundo Patrícia, o que a ajudou a contar foi o fato de ter sentido confiança e tranqüilidade na pesquisadora, sabendo que o que foi falado não será revelado a nenhum de seus conhecidos:

[...] talvez foi você que me deixou tranqüila. Assim, me mostrou confiança. Tranqüilidade. Eu sei que o que eu falei aqui, você não vai falar pra ninguém, jamais. E mesmo se você vier comentar, vai ser com quem nunca me viu. Que nunca vai me ver. Entendeu? Não é nem um vizinho, não é nenhum amigo, não é colega, não é com ninguém

Luiza e Rosa, diagnosticadas como distrofia simpático reflexo e paralisia de mão, respectivamente, relatam que nunca falaram com nenhum profissional de saúde, pois normalmente eles não têm tempo para ouvir, e também porque não perguntaram nada a respeito:

[...] porque o tempo deles [dos médicos] também é corrido, principalmente o dela [a médica] que atende muita gente, a gente nem tem tempo de falar tudo, muito boa no atendimento também, mas nunca conversamos sobre isto não.

As pacientes, de forma geral, gostaram muito da oportunidade de poderem falar sobre suas vidas, principalmente das histórias de violência. Para Patrícia, a entrevista funcionou como um desabafo, onde ela se tranqüilizou e ficou mais aliviada: 
[...] eu tô me sentindo assim tranqüila de ter falado. Desabafado uma coisa muito vergonhosa. Muito vergonhoso isso. E agora eu tô me sentindo assim mais aliviada.

Neli relata o quanto guardar as histórias só pra si, e não contar pra ninguém, pode causar revolta e muita raiva, a ponto de provocar tragédias:

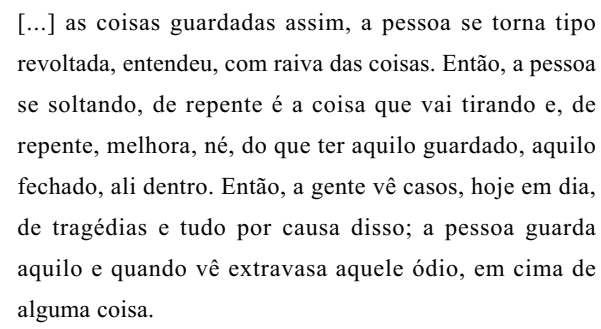

A paciente Rosa relata ter sido encaminhada para atendimento especializado com algum profissional da saúde mental, mas não procurou por medo de não ser entendida:

[...] uma vez uma pessoa me falou que era para eu procurar este tipo de ajuda, e eu tinha receio de falar estas coisas, que ficam guardadas dentro de você, que nem todo mundo vai entender

Rosa gostou muito da entrevista, de poder encontrar alguém que a ouvisse e a entendesse:

[...] me ajudou bastante, te agradeço muito. Ah! Me ajudou. Eu tava com isto tão preso. Sabe, às vezes dá vontade de chorar, aquela angústia, parece assim uma coisa presa. Agora dá até pra respirar melhor.

Assim como relata Teresa, que sentiu alívio pois, alguém a "aturou", a "ouviu" contar sua história:

[...] foi como uma espécie de alívio, né? Conversei, conversei, a senhora me aturou, me ouviu, né? E a gente fica assim, aliviada, mais leve. Porque são coisas, que de vez em quando a gente lembra, lembra, lembra. Não tem com quem conversar. Como eu disse, o meu passado, foi assim um passado amargo.

\section{Discussão}

Estudos assinalam que muitos pacientes nos atendimentos de atenção primária não verbalizam queixas de problemas pessoais, porém uma vez indagados diretamente, prontamente relatam seus problemas emocionais. 19,20 Alguns pacientes, quando procuram seus médicos, chegam a mencionar tristeza e ansiedade no início da entrevista, juntamente com suas queixas somáticas, mas somente estas últimas são valorizadas pelo profissional.

O caso de Patrícia é paradigmático com relação aos casos de dor, conforme se pode atestar na Clínica do HUPE, onde se procedeu esta pesquisa e também ao que foi observado em outros estudos. 21 Destacam-se alguns aspectos que parecem compor um determinado 'roteiro' que se verifica na maioria dos casos em questão. Resumidamente poderia ser assim colocado: há uma busca incansável de uma causalidade física para a explicação do quadro de dor, e, com isso, tem início um efeito "ping-pong", como atesta Patrícia, quando um médico encaminha para outro e assim por diante, ou o chamado efeito doctor shopping, que diz respeito à passagem da paciente de um médico para outro pelo desejo da própria paciente. $\mathrm{O}$ segundo aspecto tem a ver com as possíveis leituras da dor, ou seja, a forma como essas mulheres lidam com a dor, como a interpretam. $\mathrm{O}$ terceiro aspecto diz respeito à postura do profissional de saúde diante desse quadro.

Simon et al.22 demonstraram que os profissionais de saúde, por terem dificuldade em lidar com os aspectos subjetivos do sofrimento de seus pacientes, tendem a acatar e aceitar melhor pacientes com queixas físicas, o que funciona como importante reforço desse padrão de comportamento nos nossos pacientes. Brasil19 e Goldberg e Huxley23, destacaram que as queixas somáticas funcionam como um passaporte para o atendimento médico, pois queixas psíquicas normalmente provocam reações de afastamento e abandono por parte dos profissionais. Porém, se por um lado as queixas somáticas facilitam o acesso ao sistema de saúde, por outro lado atrapalham a descoberta do correto diagnóstico do transtorno mental que as acompanha.

Assim, o atendimento é tradicionalmente voltado para aspectos físicos e essa visão está impregnada tanto nos profissionais como nas pacientes. A busca por vias mais fáceis e rápidas para a cura, como o remédio e a religião, por exemplo, evita a necessidade de olhar para problemas tão dolorosos para as pacientes e tão complexos para a atuação do profissional.

Ao se pensar em propostas para que esse contínuo de histórias familiares de violência cesse, ou ao menos diminua, torna-se fundamental a intervenção dos profissionais de saúde. Como afirma Venguer et al.,24 a mulher nem sempre chega ao caminho da recuperação por si mesma. Nesse sentido, é necessário que a equipe de saúde compreenda a importância de sua intervenção e se 
prepare de maneira correta para tal. Que esses profissionais - médicos(as), enfermeiros(as), auxiliares de saúde, psicólogos e assistentes sociais - reconheçam a violência que se estabelece no âmbito doméstico em geral, e especificamente aquela que se perpetua contra a mulher, como um problema de saúde pública. Que se dêem conta de que os serviços de saúde são espaços ideais para a detecção desses casos, já que cedo ou tarde as mulheres vão a uma consulta por uma ou outra razão. Chamou a atenção no presente estudo, como também em outros estudos, 25,26 o fato de as mulheres terem informado que, embora já tenham "peregrinado" por vários serviços em busca de resolução para as queixas de dor, jamais foram questionadas sobre história de violência na vida delas.

Por outro lado, busca-se que o registro adequado de casos de violência sirva para demonstrar às autoridades governamentais a magnitude do problema e que ações e medidas de assistência e prevenção possam ser adotadas. Considera-se que o grande valor da atenção à saúde reside no impacto que terá na qualidade de vida das vítimas, e essa qualidade depende, entre outros fatores, do tipo de atendimento, do compromisso profissional, das medidas de maior ou menor abrangência que se adotam, tanto no atendimento como na prevenção dos casos de violência. Em outras palavras, a verdadeira assistência, em sentido amplo, visa, em última instância, a promoção da saúde.

Essa é uma importante lição que pode ser tirada do presente estudo. A partir dele as pacientes tiveram a oportunidade de falar sobre suas vidas, fizeram uma catarse ao longo das entrevistas e, em alguns casos, foram capazes de ter insights, como nos casos em que associavam a história de violência pregressa

\section{Referências}

1. Wurtele SK, Kaplan GM, Keairnes M. Childhood sexual abuse among chronic pain patients. Clin J Pain. 1990; 6: 110-3.

2. Walling MK, Reiter RC, O'Hara Mw, Milburn Ak, Lily G, Vincent SD. Abuse history and chronic pain in women: I. Prevalences of sexual abuse and physical abuse. Obstet Gynecol. 1994; 84: 193-9.

3. Walling MK, Reiter RC, O'Hara Mw, Milburn Ak, Lily G, Vincent SD. Abuse history and chorinc pain in women II. Prevalences of sexual abuse and physical abuse. Obstet Gynecol. 1994; 84: 200-6.

4. Toomey CT, Seyille J, Mann D, Abashian SW, Grant JR. Relationship of sexual and physical abuse to pain description, coping, psychological distress, and health-care utilization in a chronic pain sample. Clin J Pain. 1995; 11: 30715 . à dor contemporaneamente sentida. Tal dado reforça, mais uma vez, a ausência de atuação dos profissionais de saúde na assistência e prevenção da violência, bem como a necessidade da mesma.

Fica claro também que o sentimento de impotência, tantas vezes alegado e apontado como barreira pelos profissionais de saúde que prestam atendimento, pode e deve ser ultrapassado.

De acordo com Venguer et al., ${ }^{24}$ além desse sentimento de impotência, existem ainda os seguintes obstáculos: a) os profissionais sentem incômodo quando se identificam com seus pacientes, negando, portanto, a possibilidade da violência; b) têm medo de ofender e serem invasivos em um tema e área que culturalmente se consideram privados; c) podem ser incrédulos quanto à história do paciente; d) sentem que perdem o controle diante de pacientes cuja resolução do problema de violência dependa deles mesmos; e) alegam excesso de trabalho e falta de tempo para atender toda a demanda; e f) desconhecem a magnitude do problema, achando que a violência doméstica é pouco freqüente e não vale a pena investigá-la em seu atendimento.

Visto que os três temas estudados - dor, violência e somatização - têm fortes componentes sócioculturais, torna-se necessário para o profissional de saúde, em seu processo de diagnóstico, não apenas se preparar para a escuta, mas também, trabalhar com uma concepção multifatorial e multidisciplinar do adoecer e do tratar. É necessário, especialmente nos casos de violência, que o atendimento seja integral (visando os aspectos físicos, mas também emocionais e a integração com a rede de referência) e humanizado (acolhida, escuta, orientação e apoio aos pacientes).
5. Roy R. Childhood abuse and chronic pain: a curious relationship? Toronto: University of Toronto Press; 1998.

6. Harlow BL, Stewart EG. Adult-onset vulvodynia in relation to childhood violence victimization. Am J Epidemiol. 2005; 161: 871-80.

7. Parish WL, Wang T, Laumann EO, Pan S, Luo Y. Intimate partner violence in China: national prevalence, risk factors and associated health problems. Int Fam Plan Perspect. 2004; 30: 174-81.

8. Fanslow J, Robinson E. Violence against women in New Zealand: prevalence and health consequences. N Z Med J. 2004; 117 (1206). Available from URL: http://www.nzma. org.nz/journal/ [2005 Mar 20]. 
9. Heise L, Pitanguy J, Gemain A. Violência contra la mujer: la carga oculta sobre la salud. Washington, DC: Organização Panamericana de la Salud; 1994.

10. Duarte LF. Da vida nervosa nas classes trabalhadoras urbanas. Rio de Janeiro: Jorge Zahar; 1986.

11. Kirmayer LJ, Young A. Culture and somatization: clinical, epidemiological and ethnographic perspectives. Psychosom Med. 998; 60: 420-30.

12. Waitzkin H, Magaña $H$. The black box in somatization: unexplained physical symptoms, culture, and narratives of trauma. Soc Sci Med. 1997; 45/46: 811-25.

13. Lipowski ZJ. Somatization: the concept and its clinical application. Am. J Psychiatry. 1988; 145:158-68.

14. Almeida APF. A dor como um pedido de socorro: investigação de histórias de violências em mulheres com dor crônica [dissertação de mestrado]. Rio de Janeiro: Instituto Fernandes Figueira da Fundação Oswaldo Cruz; 2001.

15. Pereira de Queiroz, MI. Relatos orais: do "indizível" ao "dizível". In: Sinson OM, organizador. Experimentos de história de vida (Itália/Brasil). São Paulo: Vértice; 1988. p. 44-71.

16. Minayo MCS. Ciência, técnica e arte: o desafio da pesquisa social. In: Minayo MCS, organizadora. Pesquisa social: teoria, método e criatividade. Petrópolis: Vozes; 1994. p. 929.

17. Bardin L. Análise de conteúdo. Lisboa: Edições 70; 1979.

18. Minayo MCS. O desafio do conhecimento; pesquisa qualitativa em saúde. São Paulo: Hucitec; 1992.

Recebido para em 18 de agosto de 2007

Versão final apresentada em 15 de janeiro de 2008

Aprovado em 22 de janeiro de 2008
19. Goldberg DP. The concept of a psychiatric "case" in general practice. Soc. Psychiatry. 1982; 17: 61-5.

20. Brasil MA. Pacientes com queixas difusas: um estudo nosológico de pacientes apresentando queixas somáticas múltiplas e vagas [tese doutorado]. Rio de Janeiro: Instituto de Psiquiatria da Universidade Federal do Rio de Janeiro; 1995.

21. Fortes S. O paciente com dor. In: Botega NJ, organizador. Prática psiquiátrica no hospital geral: interconsulta e emergência. Porto Alegre: Artmed; 2002. p. 339-51.

22. Simon G, VonKorff M, Piccinelli M, Fullerton C, Ormel J. An international study of the relation between somatic symptoms and depression. N Engl J Med. 1999; 341: 132935 .

23. Goldberg D, Huxley P. Common mental disorders: a biosocial model. London: Routledge; 1992.

24. Venguer T, Rawcett G, Vernon R, Pick S. Violencia domestica: un marco conceptual para la capacitación del personal de salud. Population Council/INOPAL III 1998. Available from: http://www.popcouncil.org [2004 Dec 9]

25. Schraiber LB, D'Oliveira AFPL, França Junior I, Strake SS, Oliveira EA. A violência contra mulheres: demandas espontâneas e busca ativa em unidade básica de saúde. Saúde Soc. 2000; 9: 3-5.

26. Deslandes SF, Gomes R, Silva CMFP. Caracterização dos casos de violência doméstica contra a mulher atendidos em dois hospitais públicos do Rio de Janeiro. Cad Saúde Pública. 2000; 16: 129-37. 